\title{
Topografia do cone medular no lobo-guará (Chrysocyon brachyurus Illiger, 1815)
}

\section{Topography of the medullar cone in the guara wolf (Chrysocyon brachyurus Illiger, 1815)}

\author{
Gilberto Valente Machado, ${ }^{\star}$ Cláudio César Fonseca, ${ }^{\star \star}$ Marco Túlio David das Neves, ${ }^{\star \star}$ Tarcízio Antônio Rego de Paula, ${ }^{\star \star}$ \\ Laércio dos Anjos Benjamin**
}

\begin{abstract}
Resumo
Visando o conhecimento da topografia do cone medular, foram dissecados cinco lobos guará (Chrysocyon brachyurus) adultos, três machos e duas fêmeas, tendo sido verificado que o comprimento médio daquela porção da medula espinhal foi de cerca de $6,5 \mathrm{~cm}$. A base do cone medular, formada pelo sexto segmento lombar da medula espinhal, mostrou-se apoiada sobre a terceira vértebra lombar (L3) e seu ápice, mais freqüentemente, sobre a quinta vértebra lombar (L5) ou, em igual proporção, sobre a junção entre a quinta e a sexta vértebras lombares, podendo ainda atingir a sexta daquelas vértebras (L6). O fundo de saco dural apresentou sua extremidade junto à margem caudal da sétima vértebra lombar (L7) ou próximo à margem cranial da primeira vértebra sacral (S1).
\end{abstract}

Palavras-chave: anatomia, cone medular, lobo-guará.

\begin{abstract}
Seeking the knowledge of the topography of the spinal cord end, or medullar cone, five adults guara wolves (Chrysocyon brachyurus), three males and two females, were dissected, having been verified that the medium length of that portion of the spinal cord was about $6.5 \mathrm{~cm}$. The base of the medullar cone, formed by the sixth lumbar segment of the spinal cord, it was shown leaning on the third lumbar vertebra (L3) and your apex more frequently on the fifth lumbar vertebra (L5) or, equally, on the junction between fifth and sixth lumbar vertebrae; could still reach sixth of those vertebrae (L6). The dural sac presented your extremity close to the caudal margin of the seventh lumbar vertebra (L7) or close to the cranial margin of the first sacral vertebra (S1).
\end{abstract}

Keywords: anatomy, medullar cone, guara wolf.

\section{Introdução}

O lobo-guará (Chrysocyon brachyurus) é o maior canídeo selvagem da América do Sul, habita a quase totalidade do território brasileiro, apresenta coloração avermelhada em sua pelagem, tendo parte da face, bem como o dorso e extremidades dos longos membros, de coloração escura. Seus membros pélvicos são mais longos que os torácicos, o que Ihe dá um certo aspecto desajeitado. Trata-se de animal de hábitos solitários e furtivos e sua alimentação consiste desde roedores, aves, ovos, répteis e insetos, até frutas, canade-açúcar e mel. A preocupação com a sua preservação tem merecido a atenção de numerosos pesquisadores, que vêmse detendo ao estudo dos seus hábitos e exigências territoriais. Entretanto, do ponto de vista da sua morfologia, pressuposto básico para o entendimento de sua fisiologia, pouquíssimas são as informações encontradas na literatura, prendendo-se aquelas aos seus aspectos gerais e externos.
Considerando a importância de se atrelar o conhecimento da anatomia à sua aplicação prática e, neste caso, em atenção à premência das informações sobre a anatomia dos animais silvestres, da fauna brasileira, o presente trabalho tem por objetivo a descrição das relações topográficas da extremidade da medula espinhal do lobo-guará, com vistas à sua aplicação nas anestesias epidurais.

A eficiência, a segurança e a rapidez dos métodos de anestesia epidural têm por base o necessário conhecimento da anatomia da região implicada (Hopkins, 1935). Numerosos são os autores que se dedicaram ao tema, nas diferentes espécies domésticas, resultando registros como em Kappers (1936), Habel (1951), Seiferle (1951), Barry (1956), Schwarze e Schröder (1972), Getty (1975), Bruni e Zimmerl (1977), Santiago et al. (1990) e Dyce et al. (1997). Em espécies não-domésticas, vale mencionar os trabalhos de Machado et al. (1992), realizado em sagüis (Calitrix jacus jacus), e Machado et al. (1999) em lobosmarinhos (Arctocephalus australis).

* UFPR/Campus Palotina - C.P. 54 - CEP 85950-000 - Palotina, PR - machadogv@yahoo.com.br

** UFV - Dep. de Veterinária - CEP 28750-000 - Viçosa,MG - fonseca@ mail.ufv.br 
Referências específicas ao cão (Canis familiares) são feitas por Santiago (1974) que, sem referir-se aos segmentos da medula espinhal, afirma que o cone medular tem sua base situada na altura da terceira vértebra lombar (L3) e sua extremidade, assim como o início do filamento terminal se situa mais freqüentemente na metade da sétima vértebra lombar (L7), podendo ser encontrada ainda entre a sexta e sétima daquelas vértebras (L6 e L7). Afirma ainda esse autor que o fundo de saco dural alcança a primeira vértebra lombar (L1), podendo estender-se até a segunda (L2). Fletcher (1979) afirma que, em cães de grande porte, a extremidade do cone medular acha-se na altura da margem cranial da sétima vértebra lombar (L7), ao passo que em cães de pequeno porte aquela extremidade encontra-se ao nível da sexta vértebra lombar (L6). Entretanto, Evans e de Lahunta (1994), nesta mesma espécie, admitem que o cone medular tem sua base formada pelo sétimo segmento lombar da medula espinhal (L7) e que seu ápice é constituído pelo último segmento caudal (Ca5) e afirmam encontrar-se este na altura da sexta vértebra lombar (L6).

\section{Material e método}

Para a realização do presente trabalho utilizaram-se cinco espécimes adultos de lobo-guará (Chrysocyon brachyurus), três machos e duas fêmeas, todos vítimas de atropelamentos na região da Zona da Mata Leste do estado de Minas Gerais, nos arredores do município de Viçosa. Esses animais deram entrada, já em óbito ou prestes, no Hospital Veterinário da Universidade Federal de Viçosa, no transcurso da década de 1980, de onde foram encaminhados ao Laboratório de Anatomia Veterinária. Após a sua fixação em solução aquosa de formol a $10 \%$, os mesmos foram submetidos à dissecação. Para a obtenção dos resultados que ora se expõem, promoveu-se o afastamento da pele e de toda a musculatura epiaxial da região lombo-sacral de cada um dos animais, até evidenciarem-se as vértebras regionais. Em seguida removeram-se os arcos vertebrais, expondo, assim, o canal vertebral e os componentes anatômicos que o ocupam. Na seqüência, após a remoção dos plexos venosos vertebrais e tecido adiposo circunjacente, expôsse a dura-máter, sobre a qual procedeu-se uma incisão longitudinal em toda a extensão da área em dissecação. A partir de então, registraram-se os aspectos anatômicos de interesse, em especial do ponto de vista topográfico, com ênfase para o cone medular, desde sua base até o seu ápice, bem como o fundo de saco dural, seguindo-se a elaboração de esquemas representativos das modalidades encontradas. As medidas foram tomadas com o uso de paquímetro e registros fotográficos realizados, visando a documentação e exposição dos resultados.

\section{Resultados}

Após dissecações realizadas em cinco lobos guará (Chrysocyon brachyurus), objetivando conhecer as relações topográficas do cone medular, tendo sido confirmada a presença de sete vértebras lombares, verificou-se que aquele cone possui um comprimento médio, de sua base ao ápice, de $6,5 \mathrm{~cm}$. A base do cone medular era formada, em todos os exemplares examinados, pelo sexto segmento lombar da medula espinhal (L6) e estava apoiado sobre a extremidade caudal da terceira vértebra lombar (L3). O ápice do cone medular, cujo segmento de medula que o compõe não foi possível definir, pelo método utilizado, teve sua extremidade localizada na altura do corpo da quinta vértebra lombar (L5) em dois casos $(40,0 \%)$, ambos animais machos; na junção da quinta e sexta vértebras lombares (L5/L6) em outros dois exemplares $(40,0 \%)$, sendo um macho e uma fêmea; ao nível da sexta vértebra lombar (L6) no outro espécime examinado, fêmea $(20,0 \%)$. Quanto ao fundo de saco dural, sua extremidade caudal foi encontrada junto à margem caudal da sétima vértebra lombar $(\mathrm{L} 7)$ em três animais $(60,0 \%)$, sendo dois machos e uma fêmea, e junto à margem cranial da primeira vértebra sacral (S1) nos demais espécimes $(40,0 \%)$, um macho e uma fêmea.

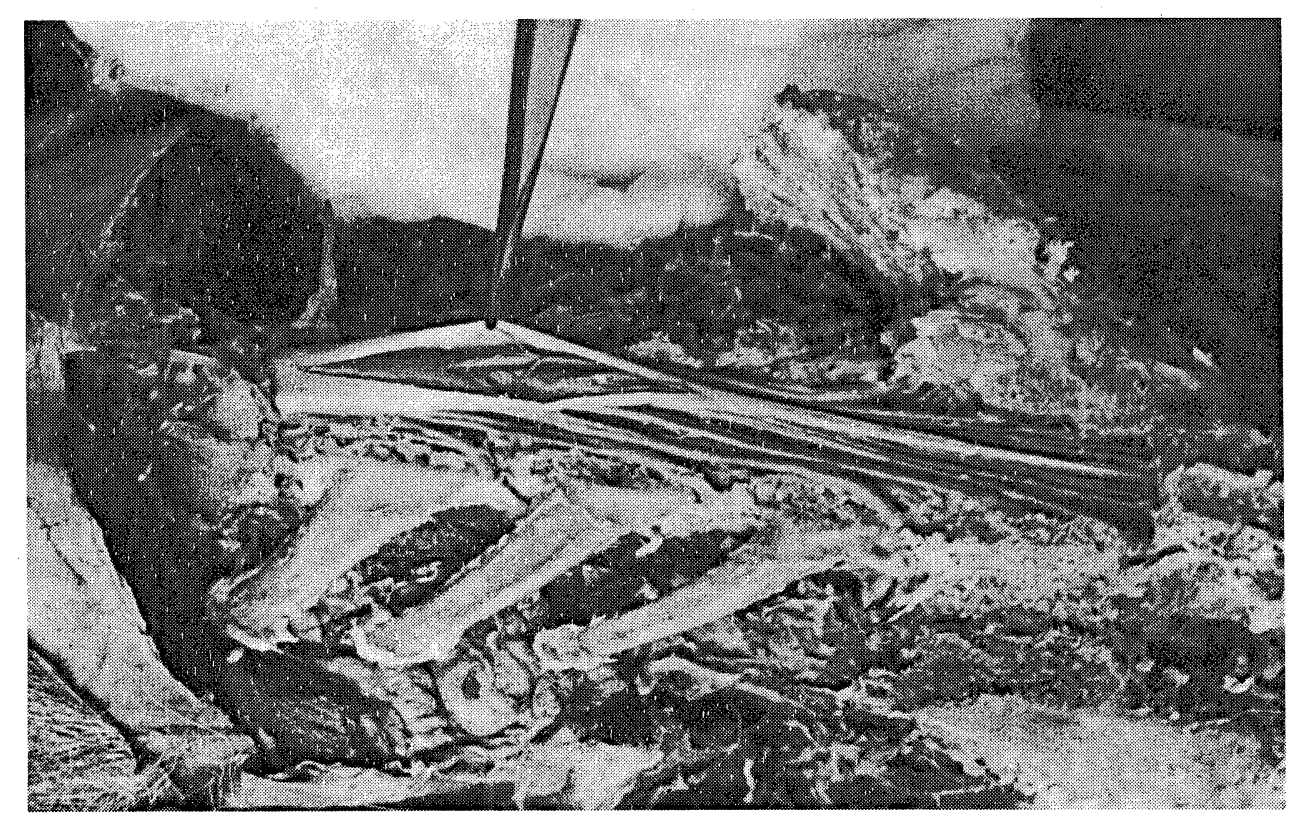

Figura 1: Vista dorsolateral esquerda do cone medular (2) de um exemplar de lobo-guará (Chrysocyon brachyurus), envolto pelo fundo de saco dural (1), após a remoção dos arcos vertebrais e exposição do canal vertebral lombossacral. Evidenciam-se ainda a cauda eqüina (3) e os processos transversos da quinta (L5), sexta (L6) e sétima (L7) vértebras lombares.

\section{Discussão}

A topografia do cone medular de diferentes espécies animais tem sido abordada por numerosos autores, os quais destacam-na tanto pelo interesse da anatomia comparativa quanto pela importância que assume nas anestesias epidurais. Enquadram-se, aqui, os enfoques dados por Hopkins (1935), 
Kappers (1936), Habel (1951), Seiferle (1951), Barry (1956), Schwarze e Schröder (1972), Getty (1975), Bruni e Zimmerl (1977), Santiago et al. (1990) e Dyce et al. (1997), reportandose aos animais domésticos de maneira geral, assim como os dados relativos a outras espécies, como em Machado et al. (1992 e 1999). Entretanto, ressalvado o interesse geral, tendo em conta a Ordem a que pertence o lobo-guará, dos carnívoros, serão relevadas as informações exaradas por Santiago (1974) que, reportando-se ao Canis familiaris, afirma que o cone medular tem sua base localizada junto à terceira vértebra lombar (L3), posição esta confirmada nos exemplares de lobos-guará ora investigados. Quanto à extremidade do cone medular, aquele autor a anuncia como estando, mais freqüentemente, ao nível da metade da sétima vértebra lombar (L7), o que não se confirmou na espécie ora pesquisada, que a apresentou em posição ligeiramente mais cranial, seja na altura da quinta vértebra lombar (L5), entre a quinta e a sexta vértebras lombares, ou junto à sexta vértebra lombar (L6). No que tange ao fundo de saco dural, aquele autor o observou estendendo-se, até mesmo, à segunda vértebra sacral, fato que também não teve equivalência nos atuais achados, que o registram mais cranialmente, ou seja, na altura da extremidade caudal da sétima vértebra lombar (L7) ou extremidade cranial da primeira vértebra sacral (S1). Quando comparados os dados aqui apresentados com aqueles anunciados por Fletcher (1979), referindo-se ao Canis familiaris, nota-se maior semelhança com os dados referentes ao cão de pequeno porte, como destacado por aquele autor; o que, com as devidas ressalvas, causa surpresa, haja

\section{Referências}

BARRY, A. A quantitative study of praenatal changes in angulation of spinal nerves. Anat. Rec., v. 126, n. 1, p. 97-109, 1956.

BRUNI, A.C.; ZIMMERL, U. Anatomia degli animali domestici. Milano: Francesco Vallardi, 1977. v. 2, p. 536.

DYCE, K.M.; SACK, W.O.; WENSING, C.J.G. Tratado de anatomia veterinária. 2. ed. Rio de Janeiro: Guanabara Koogan, 1977. p. 215239.

EVANS, H.E.; de LAHUNTA, A. Miller guia para a dissecção do cão. 3. ed. Rio de Janeiro: Guanabara Koogan, 1994. p. 197.

FLETCHER, T.F. Spinal cord and meninges. In: EVANS, H.E.; CHRISTENSEN, G.C. Miller's anatomy of the dog. 2. ed. Philadelphia: W.B. Saunders Company, 1979. p. 947.

GETTY, R. Sisson and Grossman's the anatomy of the domestic animals. 5. ed. Philadelphia: W.B. Saunders Company, 1975. v. 1, p. 202-204.

HABEL, R.E. Guide to the dissecation of the Cow. New York: Cornell Cooperative Society, 1951. p. 41.

HOPKINS, G.S. The correlation of anatomy and epidural anesthesia in domestic animals. The Cornell Veterinary, v. 25, p. 263-274, 1935. vista o porte grandioso e longilíneo do lobo-guará, o que meIhor se coadunaria com o cão de grande porte. Entretanto, quando comparados os presentes achados às afirmativas de Evans e de Lahunta (1994), estes com base no Canis familiaris, confirma-se a semelhança entre as duas espécies, quando comparadas as posições da extremidade do cone medular, ou seja, com predomínio sobre a sexta vértebra lombar (L6). Destoando, no entanto, no que tange ao segmento de medula que constitui a base do cone medular, que no cão é informado como sendo o $L 7$, ao passo que no loboguará confirmou-se ser formado pelo segmento L6.

\section{Conclusões}

As observações realizadas, após dissecação de cinco exemplares adultos de lobos guará (Chrysocyon brachyurus), sobre a topografia do seu cone medular, permitem afirmar que: a) o cone medular, que constitui a extremidade caudal da medula espinhal e tem comprimento aproximado de $6,5 \mathrm{~cm}$, tem sua base formada pelo sexto segmento lombar da medula espinhal e apoiada sobre a terceira vértebra lombar (L3); b) a extremidade do cone medular, onde tem início o filamento terminal da medula espinhal, acha-se na altura da quinta vértebra lombar (L5) ou, em igual proporção, da junção entre a quinta e a sexta vértebras lombares, podendo ainda estender-se até a sexta vértebra lombar (L6); c) o fundo de saco dural encontra-se tanto junto à margem caudal da sétima vértebra lombar (L7), quanto próximo à margem cranial da primeira vértebra sacral (S1).

KAPPERS, C.U.A. The comparative anatomy of the nervous sistem of vertebrates including man. New York: The Macmillan Company, 1936. v. 1, p. 222.

MACHADO, G.V.; RIELLA, A.C.M.; LIEGEL, S.R. Esqueletopia do cone medular em Calitrix jacus jacus. CONGRESSO BRASILEIRO DE MEDICINA VETERINÁRIA, 22., 1992, Curitiba. Anais..., 1992. p. 56.

MACHADO, G.V.; MIGLINO, M.A.; LESNAU, G.G.; MELLO, A.B.; BARBOSA, G.S. Aspectos anatômicos do cone medular no lobo-marinho (Arctocephalus australis). CONGRESSO ESTADUAL DE MEDICINA VETERINÁRIA, 14. e CONGRESSO DE MEDICINA VETERINÁRIA DO CONE SUL, 3., 1999, Gramado. Anais..., 1999. p. 88.

SANTIAGO, W. Esqueletopia do cone medular em Canis familiaris. Arq. Univ. Fed. Rur. Rio de Janeiro, v. 4, n. 1, p. 67-69, 1974.

SANTIAGO, W.; MACHADO, G.V.; VIZIOLI, V.P.; BARRA, P.H.M. Esqueletopia do cone medular em caprinos mestiços. CONGRESSO MINEIRO DEMEDICINA VETERINÁRIA, 9., 1990, Belo Horizonte.Anais..., 1990. p. 107.

SCHWARZE, E.; SCHRÖDER, L. Compendio de anatomía veterinaria. Zaragoza: Acribia, 1972. p. 26-27.

SEIFERLE, E. On the topography of the equine and bovine spinal cord. Zeitschrift für Anatomie, v. 110, p. 731-784, 1951. 